Article

\title{
Mechanical Performance Characterization of Lignin-Modified Asphalt Mixture
}

\author{
Yi Zhang ${ }^{1,2, *} \mathbb{C}$, Xuancang Wang ${ }^{1, *} \mathbb{C}$, Guanyu Ji ${ }^{1}$, Zhenyang Fan ${ }^{1}$, Yuchen Guo ${ }^{1}$, Wenze Gao ${ }^{1}$ \\ and Lei Xin ${ }^{1}$ \\ 1 School of Highway, Chang'an University, Xi'an 710064, China; shenyangtumu@163.com (G.J.); \\ fzyang0828@163.com (Z.F.); 15229242490@163.com (Y.G.); gwzvim@163.com (W.G.); \\ 2019221167@chd.edu.cn (L.X.) \\ 2 Faculty of Civil Engineering and Geosciences, Delft University of Technology, Stevinweg 1, 2628 CN Delft, \\ The Netherlands \\ * Correspondence: yizhang@chd.edu.cn (Y.Z.); wxc2005@chd.edu.cn (X.W.); Tel.: +86-029-8233-4836 (X.W.)
}

Received: 16 April 2020; Accepted: 8 May 2020; Published: 10 May 2020

\begin{abstract}
Lignin, as a bio-based waste, has been utilized in the asphalt industry due to various advantages. This study aimed to investigate the effects of two lignin products (lignin powder and lignin fiber) on the mechanical properties of asphalt mixtures. The raveling, rutting, thermal and fatigue cracking resistance, and moisture susceptibility of different asphalt mixtures were respectively evaluated by the Cantabro test, wheel loading tracking test, semicircular bending test, four-point beam bending test, and freezing-thaw cyclic test. Results show that asphalt mixture with lignin powder-modified asphalt improved the overall mechanical performance. However, lignin fiber showed contradictory effects on certain mechanical properties, i.e., improved rutting resistance and thermal cracking resistance of asphalt mixture, degraded abrasion resistance, fatigue performance, and moisture stability. Therefore, cautions need to be taken when incorporating lignin fiber into asphalt mixture.
\end{abstract}

Keywords: lignin; asphalt mixture; mechanical performance

\section{Introduction}

Asphalt pavement is the most widely utilized pavement type in the world thanks to its various advantages [1]. Every year, a huge amount of asphalt binders are consumed to pave roads. It is known that asphalt is a hydrocarbon residue from the crude-oil refining process, which is nonrenewable. However, the advances in oil refinery technology have degraded both quantity and quality of asphalt, thus leading to increased costs of asphalt and needs for asphalt modification. The rising cost and environmental concerns have driven engineers to seek renewable, sustainable materials to substitute for the petroleum-based binder products or to improve the binder performance through modification [2]. Bio-based waste has got much attention in the asphalt industry due to the improvement in binder properties and environmental sustainability by shifting from fossil-based resources to bio-based resources. Bio-based resources are in favor from the sustainability point of view: They are renewable and do not contribute to climate change, as greenhouse gases are captured from the atmosphere as a result of photosynthesis in the original vegetal source [3].

In recent years, lignin products have gained a lot of attention as a partial replacement or a performance modifier for asphalt. Lignin is a cross-linked phenolic polymer. The composition of lignin varies from case to case. Normally, it is composed of benzene rings with a randomly attached hydroxyl group. [4]. Lignin is the second most abundant organic polymer on our planet. It also exists in the by-products of biofuel production and the paper making industry [5]. With regards to the 
large amount of lignin products, it will bring huge benefits to find alternative applications of lignin to further maximize the economic potential of biofuel or paper industry. Lignin is a renewable source for aromatic compounds, which has a good compatibility with asphalt. It can reinforce asphalt binder due to the cross-linked structure. It was reported to increase the rutting resistance of asphalt binder at high temperatures. However, negative effects of lignin on fatigue and thermal cracking resistance of asphalt binders have also been reported. Besides, lignin has been proven to have a high potential of anti-oxidation due to the polyphenolic structure and free radical scavenging activity. Efforts have been put to investigate its potential as an antioxidant in the asphalt binder $[6,7]$.

The above studies have demonstrated the feasibility of using lignin in asphalt binder either as a partial substitute or as a modifier. The different effects of lignin on the rheological and mechanical performance of binders were also reported. However, these findings need to be verified at the scale of mixture, which is more correlated with the asphalt pavement performance in the field. Additionally, lignin has different forms, e.g., lignin powder and lignin fibers. How these different lignin products affect the performance of asphalt mixture also deserves in-depth research.

\section{Objective and Approach}

This study aimed to investigate the effects of two lignin products (lignin powder and lignin fiber) on the mechanical properties of asphalt mixtures. The raveling, rutting, thermal and fatigue cracking resistance, and moisture susceptibility of different asphalt mixtures were respectively evaluated by the Cantabro test, wheel loading tracking test, semicircular bending test, four-point beam bending test, and freezing-thaw splitting test.

\section{Materials and Methods}

\subsection{Materials}

In the current study, basalt aggregates and limestone fillers were used, the properties of which met the requirements of "Test method of Aggregate for Highway Engineering" (JTG E42-2005). Physical and mechanical properties of aggregates are summarized in Table 1. The used asphalt binder was neat Pen-70 asphalt from Esso (Singapore). Physical and mechanical properties of asphalt are listed in Table 2.

Table 1. Physical and mechanical properties of basalt aggregates.

\begin{tabular}{ccccc}
\hline $\begin{array}{c}\text { Specific Gravity } \\
\left(\mathrm{g} / \mathrm{cm}^{\mathbf{3}}\right)\end{array}$ & $\begin{array}{c}\text { Water } \\
\text { Absorption (\%) }\end{array}$ & $\begin{array}{c}\text { Crushing } \\
\text { Value (\%) }\end{array}$ & $\begin{array}{c}\text { Asphalt } \\
\text { Affinity (\%) }\end{array}$ & $\begin{array}{c}\text { Abrasion Loss (\%) } \\
\text { (Los Angeles) }\end{array}$ \\
\hline 2.82 & 0.72 & 12.8 & $>85$ & 14.6 \\
\hline
\end{tabular}

Table 2. Basic properties of asphalt binder.

\begin{tabular}{cc}
\hline Properties & Value \\
\hline Flash point $\left({ }^{\circ} \mathrm{C}\right)$ & 272 \\
Rotational viscosity $\left(60^{\circ} \mathrm{C}, \mathrm{Pa} \cdot \mathrm{s}\right)$ & 203 \\
Wax content $(\%)$ & 1.6 \\
Density $\left(15^{\circ} \mathrm{C}, \mathrm{g} / \mathrm{cm}^{3}\right)$ & 1.032 \\
Penetration $\left(25^{\circ} \mathrm{C}, 100 \mathrm{~g}, 5 \mathrm{~s}, 0.1 \mathrm{~mm}\right)$ & 71 \\
Ductility $\left(5 \mathrm{~cm} / \mathrm{min}, 5^{\circ} \mathrm{C}, \mathrm{cm}\right)$ & 32.2 \\
Softening point $\left(\mathrm{R} \& \mathrm{~B},{ }^{\circ} \mathrm{C}\right)$ & 47.5 \\
\hline
\end{tabular}

There are two types of lignin products used in this study: Lignin powder (LP) and lignin fiber (LF), as shown in Figure 1. The wood lignin powder was extracted using the organosolv method provided by Chemical Point UG (Oberhaching, Germany). The density of the lignin powder measured by a helium pycnometer was $1.3774 \mathrm{~g} / \mathrm{cm}^{3}$, which is much lighter than aggregates and close to asphalt. 
The specific surface area measured by a dynamic vapor sorption system was $147.0593 \mathrm{~m}^{2} / \mathrm{g}$. The $\mathrm{pH}$ value of lignin fiber was 7.5, the moisture content was $1.8 \%$, and the length range was 3 to $6 \mathrm{~mm}$. The environmental scanning electron microscope (ESEM) images of the used lignin powder and fiber are shown in Figure 2. It can be seen from Figure 2a that lignin powders contain smaller fractions of particles that are crushed from larger particles. Lignin particles have a diameter ranging from 10 to $200 \mu \mathrm{m}$. The angularity of the particles was also observed.

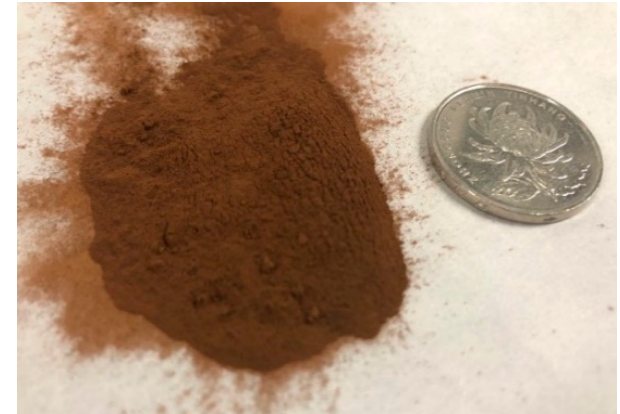

(a)

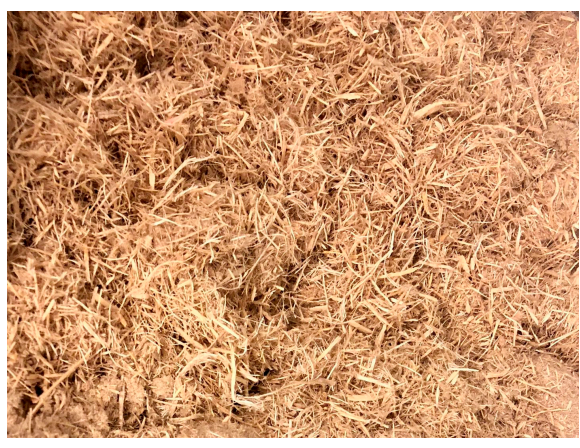

(b)

Figure 1. Visual images (a) lignin powder and (b) fibers.

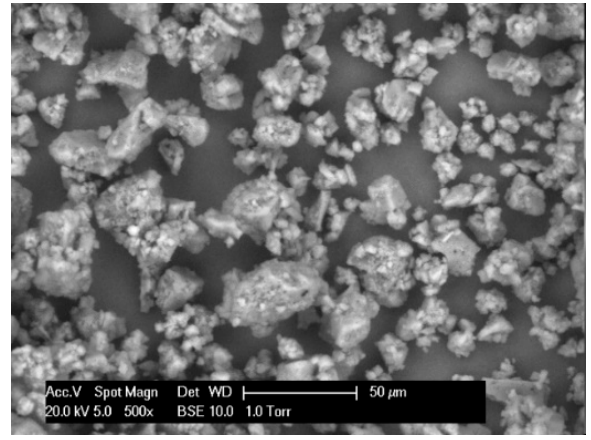

(a)

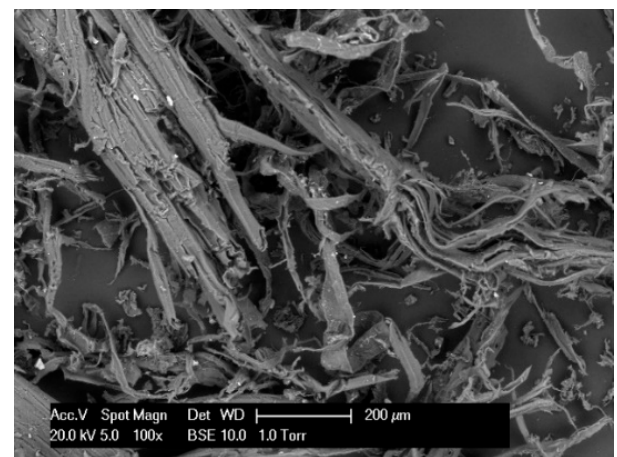

(b)

Figure 2. Environmental scanning electron microscope images of (a) lignin powder, (b) lignin fiber.

\subsection{Asphalt Mixture Design and Preparation}

Stone mastic asphalt (SMA) with a 13.2-mm nominal maximum aggregate size, denoted as SMA-13, was used as the mixture gradation for preparing mixture samples. The gradation curve of SMA-13 is shown in Figure 3 and was designed following the standard Marshall Design method (American Society for Testing and Materials D6927) [8]. The optimum asphalt content for the control SMA-13 was $6.2 \%$. The same asphalt content was used for other asphalt mixtures with lignin to minimize the control variable.

It is reported that cellulose or polyester fibers were often added into the SMA as the drain-down stabilizer [9]. In this study, lignin was incorporated into asphalt mixture instead to act as a stabilizer. Additionally, the effects of lignin on the mechanical performance of asphalt mixture were also carefully studied. To this end, the lignin powders were first mixed with neat asphalt to prepare lignin-modified asphalt. Based on previous research [2,7], the content of lignin in the modified asphalt was $10 \%$ by weight of asphalt binder, which shows better anti-aging and rheological properties. The required amount of lignin (10\% by weight of asphalt binder) was gradually added to the hot asphalt and mixed by a high shear mixing device at $163^{\circ} \mathrm{C}$ for $30 \mathrm{~min}$ with a mixing rate of $3000 \mathrm{rpm}$. Then, the prepared lignin-modified asphalt was used to prepare the asphalt mixture samples. By contrast, the lignin fibers were directly added to aggregates and asphalt to prepare the asphalt mixture samples. Based on the principle of equivalent mass of lignin, approximate $0.62 \%$ lignin by the total weight of asphalt mixture 
was used. Therefore, in total, three types of asphalt mixture samples were prepared, namely, control mix (SMA-C), lignin powder-modified asphalt mixture (SMA-LP), and asphalt mixture with lignin fiber (SMA-LF).

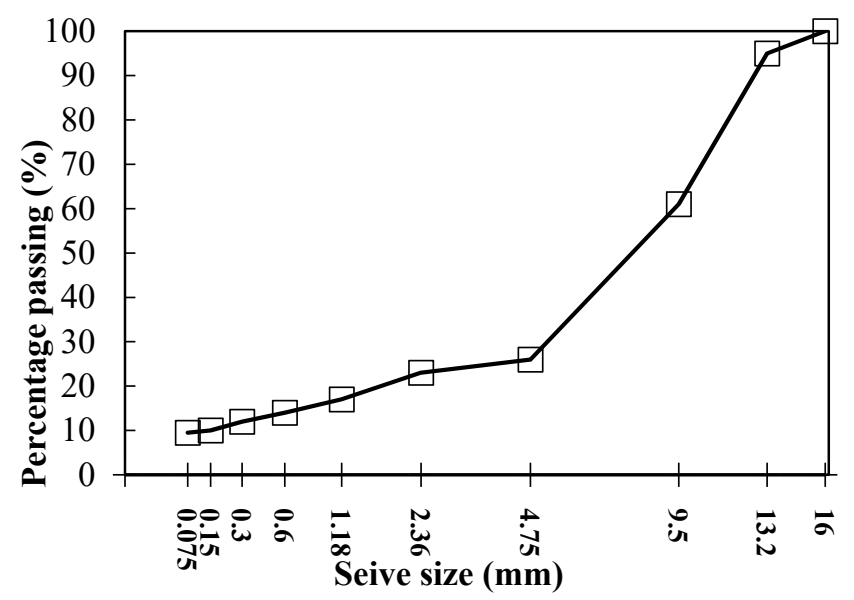

Figure 3. Mix gradation of stone mastic asphalt-13 (SMA-13).

The air voids for SMA-C and SMA-LP were around 4.0\%. The air void for SMA-LF was $4.5 \%$, slightly higher than $4.0 \%$. No separate mix designs were carried out for the mixtures containing lignin powders/fibers. This means all three types of mixture samples were prepared with the same gradation and asphalt content. The mixing and compaction temperatures were $170{ }^{\circ} \mathrm{C}$ and $155^{\circ} \mathrm{C}$, respectively. After mixing, the Hot mix asphalt (HMA) mixtures were further aged for $2 \mathrm{~h}$ at $160 \pm 5^{\circ} \mathrm{C}$ in an air-circulated oven before compaction. Specimens with different geometries were fabricated for the following performance tests.

\subsection{Laboratory Performance Tests}

\subsubsection{The Cantabro Test}

The Cantabro test was carried out to provide an indirect evaluation of abrasion resistance (e.g., raveling) for asphalt mixtures [10]. Marshall compacted specimens with a size of $101.6 \mathrm{~mm}$ in diameter and $63.5 \mathrm{~mm}$ in height were prepared. The Los Angeles abrasion machine without the steel balls was employed to obtain the Cantabro loss, which is considered as a good indicator for bonding properties between binders and aggregates. Prior to testing, the specimens were weighed and conditioned in an environmental chamber overnight at $20^{\circ} \mathrm{C}$. The machine operated at a speed of $30 \mathrm{rpm}$ for 300 revolutions. The percentage of mass loss after the test (called the Cantabro loss) was calculated as follows:

$$
\text { Cantabro loss }=\frac{m_{1}-m_{2}}{m_{2}} \times 100
$$

where $m_{1}$ is the weight of the initial sample and $m_{2}$ is the weight after the test.

\subsubsection{Wheel Loading Tracking Test}

The wheel loading tracking test is a useful tool to assess the permanent deformation resistance of asphalt mixtures. Slab specimens with a dimension of $300 \mathrm{~mm} \times 300 \mathrm{~mm} \times 50 \mathrm{~mm}$ were prepared using the roller compactor. A total wheel load of $0.78 \mathrm{kN}$ from a solid-rubber wheel was applied on the slab specimen to create a contact pressure of $0.7 \mathrm{MPa}$. The traveling speed was $42 \pm 1$ cycles per min with a total traveling span of $230 \pm 10 \mathrm{~mm}$ at $60{ }^{\circ} \mathrm{C}$. The test stopped when either test time reached $1 \mathrm{~h}$ or the maximum deformation exceeded $25 \mathrm{~mm}$. For each mix, three replicates were prepared for 
testing. Dynamic stability (DS) was calculated based on the curve of cumulative rut depths with time for the mix, as shown in Equation (2).

$$
\mathrm{DS}=\frac{\left(t_{1}-t_{2}\right) \times N}{d_{1}-d_{2}}
$$

where $t_{1}$ and $t_{2}$ correspond to the time at $45 \mathrm{~min}$ and $60 \mathrm{~min}$, respectively; $d_{1}$ and $d_{2}$ are rut depth at time $t_{1}$ and $t_{2} ; N$ is the number of cycles of wheel passes over the sample per minute. Higher DS indicates better rutting resistance of asphalt mixture.

\subsubsection{Semicircular Bending Test}

The semicircular bending (SCB) test was used to characterize the low-temperature cracking resistance of asphalt mixture. The SCB test was conducted according to the specification of American Association of State Highway and Transportation Officials (AASHTO) TP 105. A 50-mm-thick, semicircular disk specimen was cut from gyratory compacted sample of a 150-mm diameter. A 15-mm-deep and 1.5-mm-wide notch parallel to the loading axis was cut in the middle of the flat section of the specimen. The test was performed at a temperature of $-10{ }^{\circ} \mathrm{C}$. During the test, the specimen was loaded along the vertical radius monotonically to failure at a constant displacement rate of $50 \mathrm{~mm} / \mathrm{min}$. The vertical displacement and load were continuously recorded during the test.

\subsubsection{Four-Point Beam Bending Test}

Four-point beam bending fatigue testing of HMA in the laboratory has been used for several decades by many researchers to simulate field conditions, which was also performed by Universal Testing System (UTM-25) and the beam fatigue apparatus in this study [11]. Three types of asphalt mixture specimens were stored in the environmental chamber for at least $2 \mathrm{~h}$ for temperature conditioning. A controlled strain haversine loading was applied at a frequency of $10 \mathrm{~Hz}$ and a temperature of $20{ }^{\circ} \mathrm{C}$. No rest period was applied. For controlled-strain tests, the method of $50 \%$ reduction of the initial stiffness was regarded as fatigue life criteria. That means the fatigue test terminated when the flexural stiffness reached half of its initial value. Five strain levels $(300,400,500$, 600 , and $700 \mu \mathrm{m} / \mathrm{m}$ ) were adopted in the tests.

\subsubsection{Freeze-Thaw Splitting Test}

The moisture susceptibility of asphalt mixtures was evaluated using the freeze-thaw split test according to Chinese specification (JTG E20-2011) T 0729, which is comparable to AASHTO T 283. All samples were divided into two groups. The first group was stored at room temperature. The second group samples were saturated with water and stored at a temperature of $-20^{\circ} \mathrm{C}$ for $16 \mathrm{~h}$. After this, the samples were placed in a constant temperature water bath at $60^{\circ} \mathrm{C}$ for $24 \mathrm{~h}$. Before the test, the two groups of samples were placed in a $25^{\circ} \mathrm{C}$ water bath for at least two hours. The test load rate was $50 \mathrm{~mm} / \mathrm{min}$ until the failure. The capability of asphalt mixture to resist the moisture damage was indicated by the splitting tensile strength ratio (TSR). Three replicates were used for both wet and dry scenarios. The dimension of the sample was $101.6 \mathrm{~mm}$ diameter by $63.5 \mathrm{~mm}$ height.

$$
\mathrm{TSR}=\frac{R_{T 2}}{R_{T 1}} \times 100
$$

where TSR is the tensile strength ratio (\%), and $R_{T 1}$ and $R_{T 2}$ are the average tensile strength of fresh samples and frozen-thawed samples, respectively (MPa). $R_{T 2}$ and $R_{T 1}$ are calculated by Equation (4) from the indirect tensile test.

$$
R_{T}=\frac{0.006287 P_{T}}{h}
$$

where $R_{T}$ is the indirect tensile strength (MPa), $P_{T}$ is the load when sample fails $(\mathrm{N})$, and $h$ is the sample height (mm). 


\section{Results and Discussion}

\subsection{Abrasion Resistance}

The averages of Cantabro loss calculated by Equation (1) for the control mix and mix with lignin are shown in Figure 4. The SMA-LP had a Cantabro loss of 10.4\%, which was lower that of SMA-C with the Cantabro loss of $13.5 \%$. Compared with the control mix, the lignin powder-modified asphalt binder reduced the Cantabro loss values significantly, which demonstrated that the SMA-LP showed a stronger abrasion resistance. The reason for the improvement in abrasion resistance could be attributed to the increase in the adhesion force between lignin-modified asphalt and aggregate. By contrast, the SMA-LF had a higher Cantabro loss than SMA-C. The reason accounting for this finding is that the addition of lignin fiber with a relatively large size had a negative effect on the adhesion and bonding between asphalt and aggregates. The addition of lignin fiber also absorbed an amount of asphalt, which is usually believed to decrease the abrasion resistance [10]. The decrease of effective asphalt content in the mixture will degrade the abrasion resistance.

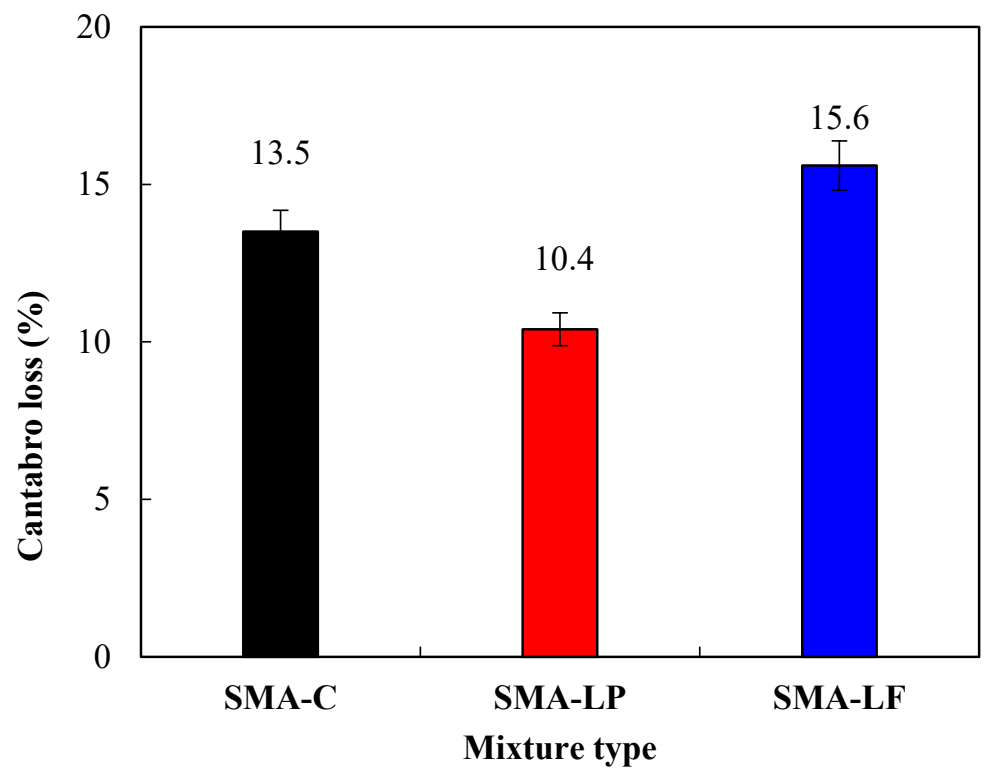

Figure 4. The Cantabro loss of different asphalt mixtures.

\subsection{Rutting Resistance}

The wheel tracking test results are shown in Figure 5. Different rutting depths as a function of time were observed. Figure 5 shows that both lignin products significantly reduced the rutting depths of asphalt mixture compared to the control one. SMA-LF had the smallest rutting depth after the loading. It can be also seen from Figure 5 that the rutting depth increased rapidly at the early stage, which is primarily because of the condensation of loose asphalt mixtures under the compressive loading pressure. Afterward, the increase rate of the rutting depth gradually dropped with time, which was primarily induced by the shear flow of asphalt mixture. Two stages of rutting development were observed. The slope of the linear line in the second stage reflected the increasing rate of rutting depth and dynamic stability. A higher slope value indicates lower dynamic stability of the material. The dynamic stability of the different mixtures calculated by Equation (2) is compared in Figure 6. Results show that SMA-LF had the highest dynamic stability followed by SMA-LP, indicating the highest rutting resistance. The reduction in rutting depth of SMA-LF can be attributed to two reasons: (1) Fibers can stabilize and keep the viscous asphalts together to resist the asphalt flowing at elevated temperatures and (2) fibers can form a three-dimensional network in the mortar, reinforcing the skeleton structure to resist the shear force $[12,13]$. For SMA-LP, lignin powders with the asphalt mixture could 
not form the three-dimensional network but did increase the high-temperature performance grade of asphalt binders, which also contributed to the increase of dynamic stability of asphalt mixture.

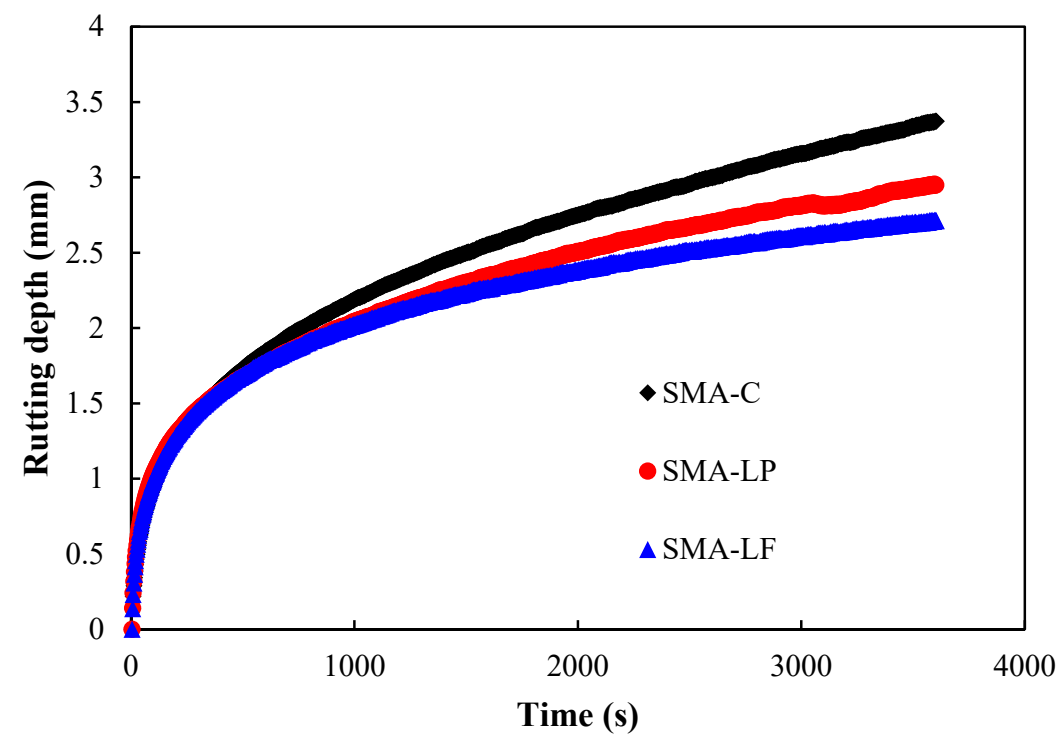

Figure 5. Rutting depth evolution with time in wheel loading tracking test.

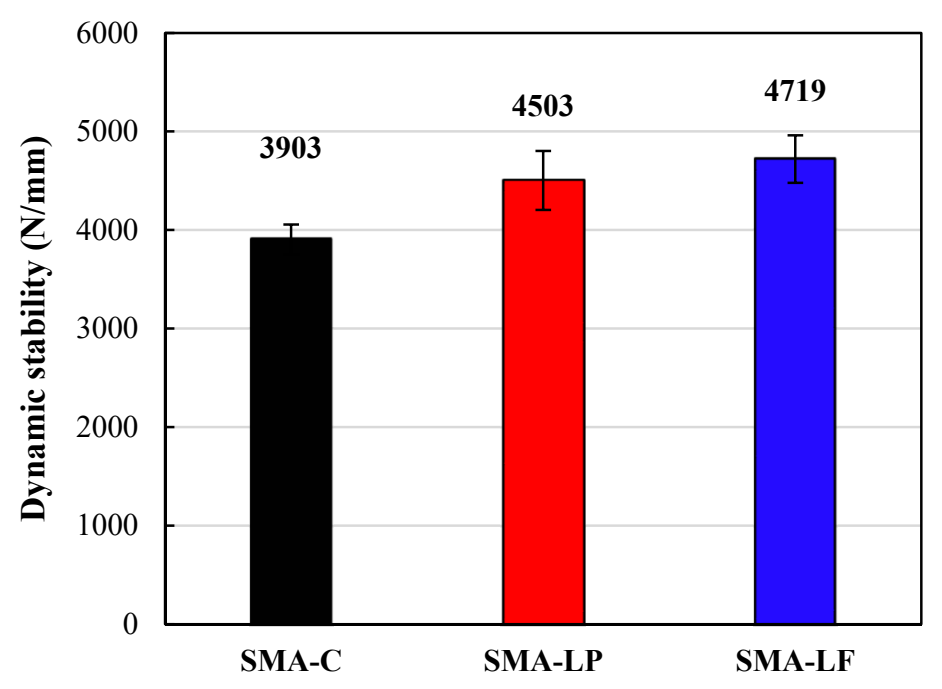

Figure 6. Dynamic stability of different asphalt mixtures.

\subsection{Thermal Cracking Resistance}

The semicircular bending (SCB) test was proposed as a fracture test to evaluate the low-temperature cracking resistance of asphalt mixtures. A typical load-displacement curve and the related parameters involved in the test are presented in Figure 7. Recently, the University of Illinois proposed the flexibility index (FI) to determine the cracking resistance of asphalt mixture [14]. It is a parameter that combines the fracture energy and post-peak failure behavior of asphalt mixture. The parameters used to derive the FI are illustrated in Figure 7. The FI is defined as the ratio of the fracture energy and the absolute value of the post-peak slope with the help of certain calibration factors. The detailed definition and calculation of each parameter can be found in reference [14]. It was reported that fracture energy alone was insufficient to discriminate among mixture design factors while FI is a valuable parameter in ranking the cracking performance of asphalt mixture [15]. Therefore, in this study, FI was used to compare the thermal cracking resistance of asphalt mixture with/without lignin. 


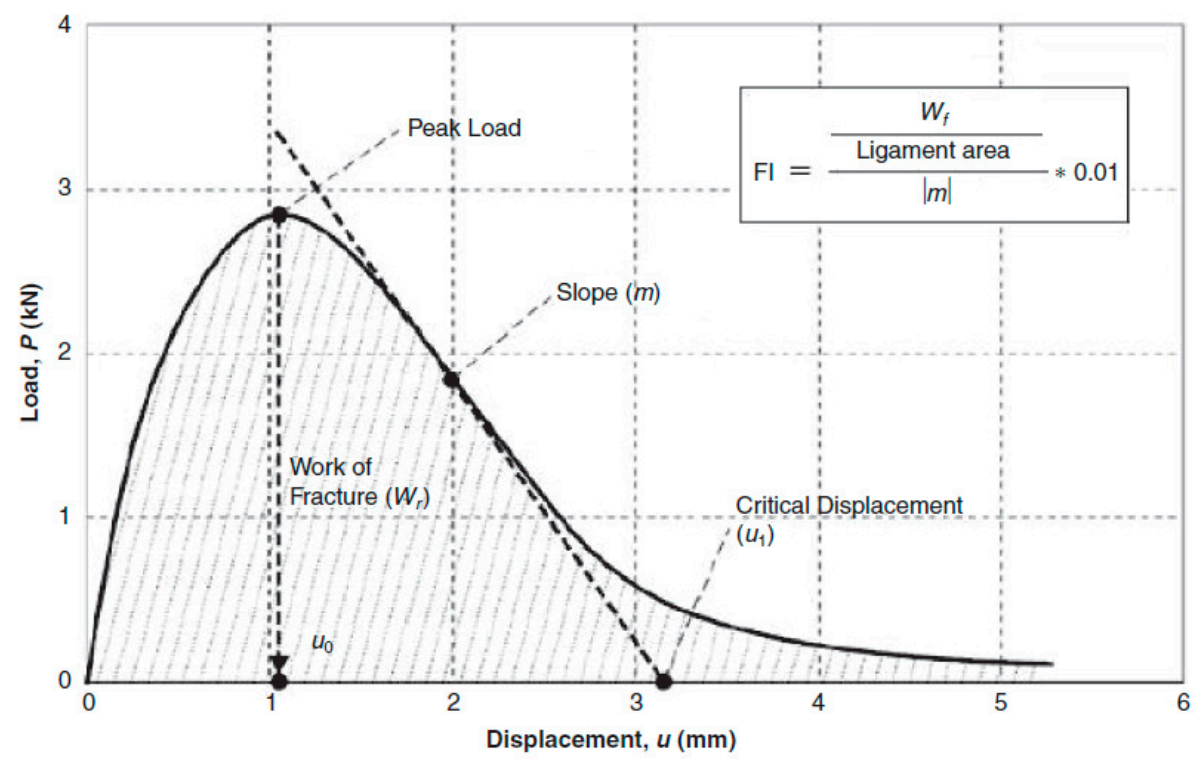

Figure 7. A typical load-displacement curve of the Semicircular bending test (SCB) test and illustrated parameters.

Figure 8 shows the load-displacement curves of different asphalt mixtures from SCB tests. It can be seen that the load peak of SMA-LP occurred at a larger displacement, indicating a better flexibility. Brittle failure of the tested samples was not observed. To independently determine the fracture potential of a mixture, Figure 9 shows the FI values of different mixtures. It can be seen that asphalt mixtures with lignin show improved FI than the control mix. SMA-LP had the highest FI of 4.6 while SMA-C had the lowest FI of 2.3. Therefore, both lignin products are beneficial to improve the cracking resistance of asphalt mixture at low temperatures. The effect of lignin powder-modified asphalt on the improvement was more prominent. Lignin-modified asphalt binder improved the adhesive properties between aggregates and mortar, which is especially helpful to resist thermal cracking. Lignin fiber also had a reinforcing effect on the microstructure of asphalt mixture, which delays the cracking.

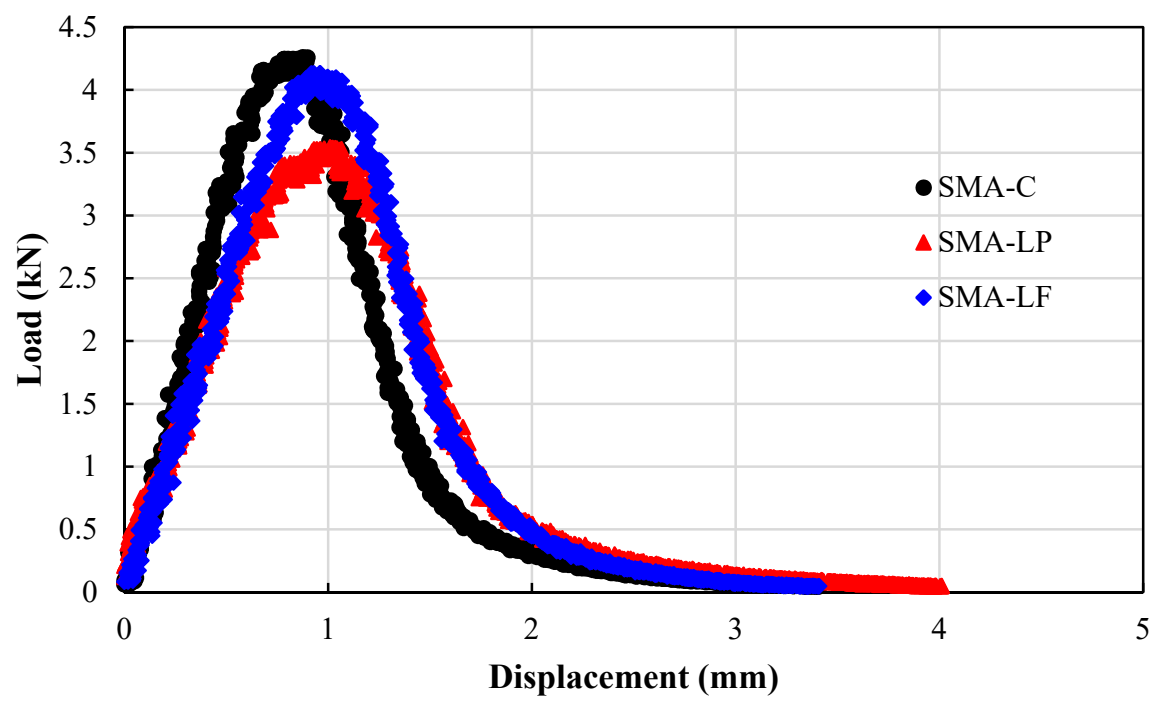

Figure 8. SCB test results of different asphalt mixtures. 


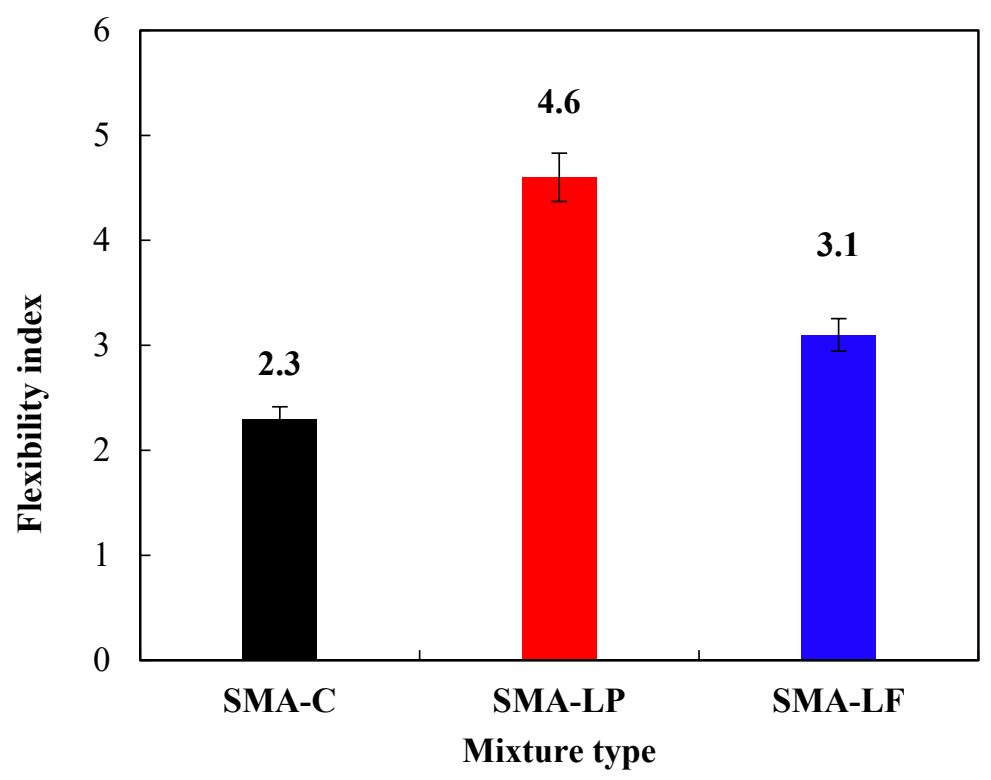

Figure 9. Flexibility index from SCB tests.

\subsection{Fatigue Performance}

Four-point beam bending tests were conducted to evaluate the fatigue resistance of asphalt mixture. The chosen fatigue resistance criterion was a 50\% loss of the initial stiffness modulus. Figure 10 presents the fatigue life values at five different strain levels of three different mixtures. It can be seen that at a certain strain level, SMA-LP had a significantly longer fatigue life than SMA-C. By contrast, SMA-LF exhibited a lesser fatigue life than SMA-C. The following fatigue law based on the phenomenological method was used to predict the fatigue life at a strain level of interest.

$$
N_{f}=a \varepsilon^{-b}
$$

where $N_{f}$ is the fatigue life (loading cycles when the specimen fails), $\varepsilon$ is the applied strain level, and $a$ and $b$ are the fitting parameters related to mixture property. For comparison, the $\varepsilon_{6}$ parameter (the strain at which specimen can endure 1 million loading cycles before failure) of different mixtures was also calculated using Equation (5). The parameters of the fatigue law and the $\varepsilon_{6}$. parameter are summarized in Table 3. The $\varepsilon_{6}$ parameter is an indicator of the fatigue resistance of asphalt mixture. The $\varepsilon_{6}$ parameter of SMA-C, SMA-LP, and SMA-LF was 251, 293, and 209, respectively. From the binder test results, it is known that lignin powder-modified asphalt binder increased the fatigue resistance [7]. It is anticipated that lignin-modified asphalt increases the adhesion between aggregates and delays the development of fatigue cracking. However, it is unexpected that the addition of lignin fiber decreases the fatigue resistance of asphalt mixture. Normally, fiber-reinforced asphalt mixture has a higher cracking resistance than normal mixture because of the bridging effect of fibers among cracks, which delays the propagation of cracking [16]. The reason for this may be due to the poor compatibility between lignin fiber and asphalt, hence, influencing the bonding between aggregates.

Table 3. Fatigue law parameters and $\varepsilon_{6}$.

\begin{tabular}{cccc}
\hline Mixture Type & $\boldsymbol{a}$ & $\boldsymbol{b}$ & $\boldsymbol{\varepsilon}_{6}$ \\
\hline SMA-C & $2.45 \mathrm{E}+17$ & 4.745 & 251 \\
SMA-LP & $1.14 \mathrm{E}+19$ & 5.293 & 293 \\
SMA-LF & $8.53 \mathrm{E}+15$ & 4.281 & 209 \\
\hline
\end{tabular}




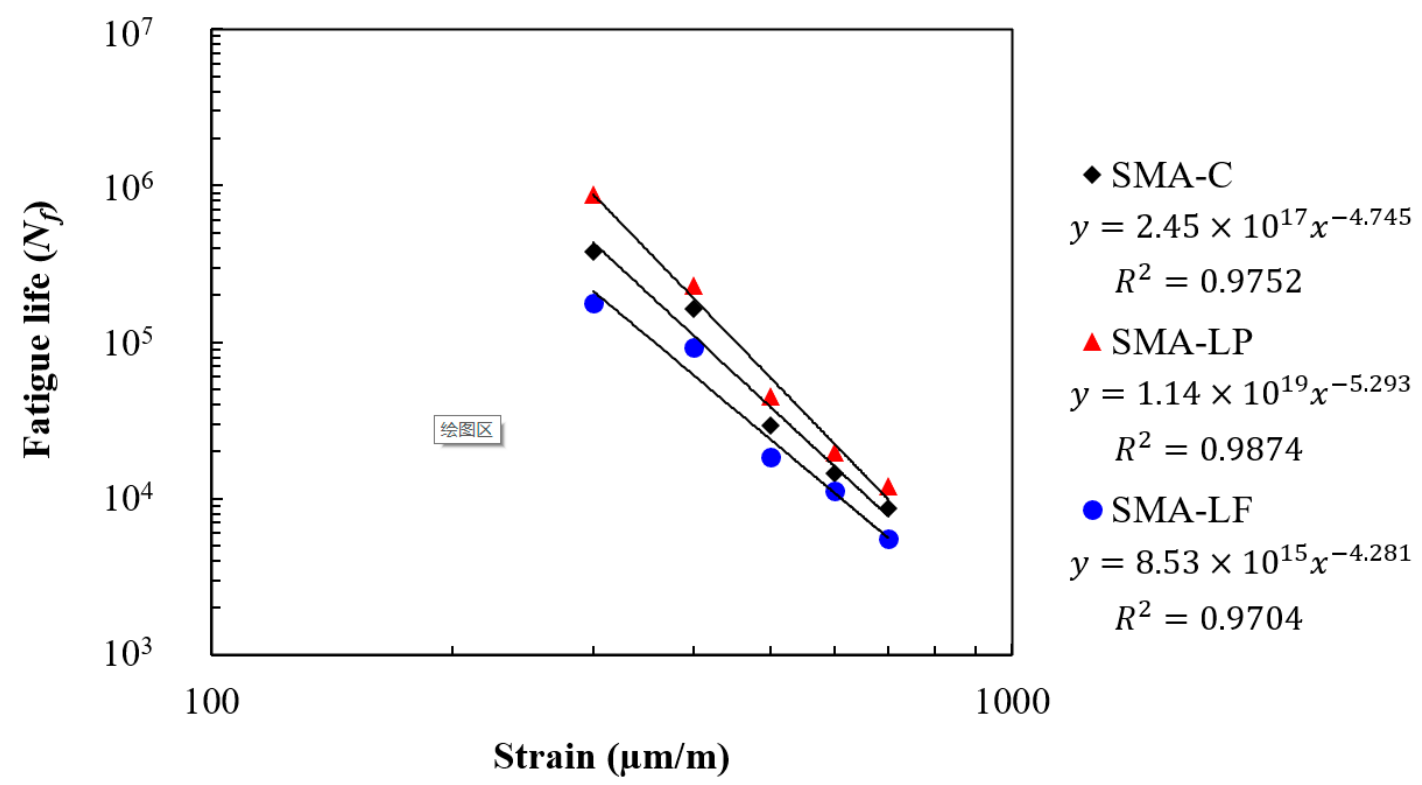

Figure 10. Fatigue life of asphalt mixture as a function of applied strain.

\subsection{Moisture Susceptibility}

Moisture susceptibility of asphalt mixture is mainly influenced by the characteristics of mineral aggregates, the asphalt-aggregate interaction behaviors, and the air void of asphalt mixture. Generally, it is easier for moisture to infiltrate aggregate surface than asphalt binder. This will reduce the adhesion between asphalt and aggregates and lead to moisture damage-related distresses (e.g., raveling) [17]. The indirect tensile strength (ITS) test results of samples at different states are summarized in Table 4 . It shows that both SMA-LP and SMA-LF had a higher ITS than the control mix, which demonstrates that lignin in asphalt mixture has a reinforcing effect when it is under the tensile stress. However, after the freeze-thaw cycle, the ITS of different asphalt mixtures degrades differently. As reflected by the TSR values, the ITS of SMA-LF degrades the most after the treatment of freeze-thaw. It implies that it had the worst moisture stability. The reason for the lower TSR value of SMA-LF could be because of its relatively large air voids after the addition of fibers. The increased air voids provide more possibilities to contain water and form ice at low temperatures, resulting in greater expanding forces inside the aggregate skeleton structure. Additionally, different thermal contraction coefficients of asphalts and fibers may cause interfacial sliding between aggregates and fibers [18]. Comparing to SMA-C, SMA-LP seems to improve the moisture stability, as indicated by the higher TSR value of $89.6 \%$. The reason for this is due to improved adhesion properties between lignin-modified asphalt binders and aggregates. Based on the specified limit of TSR value in the mix design specification, all three asphalt mixtures in this study meet the requirement of minimum TSR of $80 \%$.

Table 4. Freeze-thaw splitting test results.

\begin{tabular}{cccc}
\hline Mixture Type & $\boldsymbol{R}_{\boldsymbol{T 1}} \mathbf{( M P a )}$ & $\boldsymbol{R}_{\boldsymbol{T} 2} \mathbf{( M P a )}$ & TSR (\%) \\
\hline SMA-C & 0.97 & 0.82 & 84.5 \\
SMA-LP & 1.06 & 0.95 & 89.6 \\
SMA-LF & 1.03 & 0.83 & 80.6 \\
\hline
\end{tabular}

\section{Conclusions and Recommendation}

This study investigated the mechanical performance of asphalt mixtures modified by two lignin products (lignin powder and lignin fiber). The raveling, rutting, thermal and fatigue cracking resistance, and moisture susceptibility of different asphalt mixtures were respectively evaluated by the 
Cantabro test, wheel loading tracking test, semicircular bending test, four-point beam bending test, and freezing-thaw splitting test. The following conclusions can be drawn:

1. SMA-LP showed a stronger abrasion resistance while SMA-LF decreased the abrasion resistance. The same effects of lignin products on fatigue performance and moisture susceptibility were observed, i.e., SMA-LP improved fatigue performance and moisture stability while SMA-LF degraded them.

2. Both lignin products increased the rutting resistance and thermal cracking resistance of asphalt mixture. Lignin fiber was more efficient than lignin powder in increasing the dynamic stability while lignin powder-modified asphalt was more prominent in improving the thermal cracking performance.

3. Lignin powder-modified asphalt binder can improve the overall mechanical performance of asphalt mixture. By contrast, lignin fiber may have adverse effects on certain mechanical properties. Cautions need to be taken when incorporating lignin fiber into asphalt mixture.

For future research, the interfacial behaviors between asphalt, fiber, and aggregate need to be investigated. The adhesive properties deserve an in-depth study to explain the cracking performance of lignin-modified asphalt mixtures. And other contents of asphalt and lignin mixtures, even mixtures between powders and fibers, will be tested for further validation.

Author Contributions: Conceptualization, Y.Z. and X.W.; methodology, Y.Z. and X.W.; validation, G.J., Z.F., and Y.G.; formal analysis, W.G.; investigation, L.X.; writing-original draft preparation, Y.Z.; writing一review and editing, Y.Z., G.J., Z.F., and Y.G.; supervision, X.W. All authors have read and agreed to the published version of the manuscript.

Funding: This research received no external funding.

Acknowledgments: The first author thanks the scholarship from the China Scholarship Council.

Conflicts of Interest: The authors declare no conflicts of interest.

\section{References}

1. Wang, H.; Jun, Y.; Gong, M.; Shi, X. Laboratory Performance Evaluation of High-Modulus Asphalt Mixtures for Perpetual Asphalt Pavements, Transportation Research Board 94th Annual Meeting; Transportation Research Board: Washington, DC, USA, 2015.

2. Xu, G.; Wang, H.; Zhu, H. Rheological properties and anti-aging performance of asphalt binder modified with wood lignin. Constr. Build. Mater. 2017, 151, 801-808. [CrossRef]

3. Su, N.; Xiao, F.; Wang, J.; Cong, L.; Amirkhanian, S. Productions and applications of bio-asphalts-A review. Constr. Build. Mater. 2018, 183, 578-591. [CrossRef]

4. Arafat, S.; Kumar, N.; Wasiuddin, N.M.; Owhe, E.O.; Lynam, J.G. Sustainable lignin to enhance asphalt binder oxidative aging properties and mix properties. J. Clean. Prod. 2019, 217, 456-468. [CrossRef]

5. van Vliet, D.; Slaghek, T.; Giezen, C.; Haaksman, I. Lignin as a green alternative for bitumen. In Proceedings of the 6th Eurasphalt \& Eurobitume Congress, Prague, Czech, 1-3 June 2016.

6. Pan, T. A first-principles based chemophysical environment for studying lignins as an asphalt antioxidant. Constr. Build. Mater. 2012, 36, 654-664. [CrossRef]

7. Zhang, Y.; Liu, X.; Apostolidis, P.; Gard, W.; van de Ven, M.; Erkens, S.; Jing, R. Chemical and rheological evaluation of aged lignin-modified bitumen. Materials 2019, 12, 4176. [CrossRef] [PubMed]

8. Papagiannakis, A.T.; Masad, E.A. Pavement Design and Materials; John Wiley \& Sons: Hoboken, NJ, USA, 2017.

9. Wu, S.P.; Ye, Q.S.; Li, N. Investigation of rheological and fatigue properties of asphalt mixtures containing polyester fibers. Constr. Build. Mater. 2008, 22, 2111-2115. [CrossRef]

10. Cox, B.C.; Smith, B.T.; Howard, I.L.; James, R.S. State of knowledge for cantabro testing of dense graded asphalt. J. Mater. Civ. Eng. 2017, 29, 04017174. [CrossRef]

11. Wang, H.; Yang, J.; Lu, G.; Liu, X. Accelerated healing in asphalt concrete via laboratory microwave heating. J. Test. Eval. 2020, 48, 739-757. [CrossRef] 
12. Abtahi, S.M.; Sheikhzadeh, M.; Hejazi, S.M. Fiber-reinforced asphalt-concrete-A review. Constr. Build. Mater. 2010, 24, 871-877. [CrossRef]

13. Chen, H.X.; Xu, Q.W.; Chen, S.F.; Zhang, Z.Q. Evaluation and design of fiber-reinforced asphalt mixtures. Mater. Des. 2009, 30, 2595-2603. [CrossRef]

14. Ozer, H.; Al-Qadi, I.L.; Lambros, J.; El-Khatib, A.; Singhvi, P.; Doll, B. Development of the fracture-based flexibility index for asphalt concrete cracking potential using modified semi-circle bending test parameters. Constr. Build. Mater. 2016, 115, 390-401. [CrossRef]

15. Ling, C.; Swiertz, D.; Mandal, T.; Teymourpour, P.; Bahia, H. Sensitivity of the illinois flexibility index test to mixture design factors. Transp. Res. Rec. 2017, 2631, 153-159. [CrossRef]

16. Wang, H.; Yang, J.; Liao, H.; Chen, X. Electrical and mechanical properties of asphalt concrete containing conductive fibers and fillers. Constr. Build. Mater. 2016, 122, 184-190. [CrossRef]

17. Varveri, A.; Avgerinopoulos, S.; Scarpas, A. Experimental evaluation of long- and short-term moisture damage characteristics of asphalt mixtures. Road Mater. Pavement Des. 2015, 17, 168-186. [CrossRef]

18. Fu, Z.; Shen, W.; Huang, Y.; Hang, G.; Li, X. Laboratory evaluation of pavement performance using modified asphalt mixture with a new composite reinforcing material. Int. J. Pavement Res. Technol. 2017, 10, 507-516. [CrossRef]

(C) 2020 by the authors. Licensee MDPI, Basel, Switzerland. This article is an open access article distributed under the terms and conditions of the Creative Commons Attribution (CC BY) license (http://creativecommons.org/licenses/by/4.0/). 